\title{
Utility of intraoperative electromyography in placing C7 pedicle screws
}

\author{
Jonathan J. Rasouli, MD, ${ }^{1}$ Brooke T. Kennamer, DO, ${ }^{2}$ Frank M. Moore, MD, ${ }^{1}$ \\ Alfred Steinberger, MD, ${ }^{1}$ Kevin C. Yao, MD, ${ }^{1}$ Omar N. Syed, MD, ${ }^{1}$ Marc S. Arginteanu, MD, ${ }^{1}$ and \\ Yakov Gologorsky, MD'
}

\begin{abstract}
'Department of Neurosurgery, Mount Sinai Health System, New York, New York; and 'Department of Neurosurgery, University of Missouri, Columbia, Missouri
\end{abstract}

OBJECTIVE The C7 vertebral body is morphometrically unique; it represents the transition from the subaxial cervical spine to the upper thoracic spine. It has larger pedicles but relatively small lateral masses compared to other levels of the subaxial cervical spine. Although the biomechanical properties of $\mathrm{C} 7$ pedicle screws are superior to those of lateral mass screws, they are rarely placed due to increased risk of neurological injury. Although pedicle screw stimulation has been shown to be safe and effective in determining satisfactory screw placement in the thoracolumbar spine, there are few studies determining its utility in the cervical spine. Thus, the purpose of this study was to determine the feasibility, clinical reliability, and threshold characteristics of intraoperative evoked electromyographic (EMG) stimulation in determining satisfactory pedicle screw placement at C7.

METHODS The authors retrospectively reviewed a prospectively collected data set. All adult patients who underwent posterior cervical decompression and fusion with placement of $\mathrm{C} 7$ pedicle screws at the authors' institution between January 2015 and March 2019 were identified. Demographic, clinical, neurophysiological, operative, and radiographic data were gathered. All patients underwent postoperative CT scanning, and the position of C7 pedicle screws was compared to intraoperative neurophysiological data.

RESULTS Fifty-one consecutive C7 pedicle screws were stimulated and recorded intraoperatively in 25 consecutive patients. Based on EMG findings, 1 patient underwent intraoperative repositioning of a $\mathrm{C} 7$ pedicle screw, and 1 underwent removal of a C7 pedicle screw. CT scans demonstrated ideal placement of the C7 pedicle screw in 40 of 43 instances in which EMG stimulation thresholds were $>15 \mathrm{~mA}$. In the remaining 3 cases the trajectories were suboptimal but safe. When the screw stimulation thresholds were between 11 and $15 \mathrm{~mA}, 5$ of 6 screws were suboptimal but safe, and in 1 instance was potentially dangerous. In instances in which the screw stimulated at thresholds $\leq 10 \mathrm{~mA}$, all trajectories were potentially dangerous with neural compression.

CONCLUSIONS Ideal C7 pedicle screw position strongly correlated with EMG stimulation thresholds $>15 \mathrm{~mA}$. In instances, in which the screw stimulates at values between 11 and $15 \mathrm{~mA}$, screw trajectory exploration is recommended. Screws with thresholds $\leq 10 \mathrm{~mA}$ should always be explored, and possibly repositioned or removed. In conjunction with other techniques, EMG threshold testing is a useful and safe modality in determining appropriate C7 pedicle screw placement. https://thejns.org/doi/abs/10.3171/2019.11.SPINE191120

KEYWORDS posterior cervical fusion; pedicle screws; electromyography; intraoperative; safety; medial breach; cervicothoracic junction; surgical technique

I NDICATIONS for posterior cervical decompression, instrumentation, and fusion are broad, and include cervical spondylotic myelopathy, multilevel stenosis, pseudarthrosis after anterior cervical fusion, ossification of the posterior longitudinal ligament (OPLL), and deformity.12
Surgeons typically use a combination of the patient's clinical examination results, findings on radiographic imaging, and biomechanical considerations in determining the number of levels that are ultimately decompressed and/or fused. ${ }^{1,2,10}$ Determining the most appropriate distal fixa-

ABBREVIATIONS CMAPS = compound muscle action potentials; EMG = electromyographic; OPLL = ossification of the posterior longitudinal ligament; VA = vertebral artery. SUBMITTED September 16, 2019. ACCEPTED November 15, 2019.

INCLUDE WHEN CITING Published online January 31, 2020; DOI: 10.3171/2019.11.SPINE191120. 
tion level is controversial when considering the cervicothoracic junction, with some surgeons choosing to extend the fusion to the proximal thoracic spine instead of ending at $\mathrm{C}$, in part due to the unique morphometric properties of the $\mathrm{C} 7$ vertebral body and the challenges that its fixation presents..$^{1,2,5,6}$

The C7 vertebral body represents the transition point from the subaxial cervical spine to the upper thoracic spine. It has the largest vertebral body, longest spinous processes, and a relatively small lateral mass compared to other subaxial cervical levels., ${ }^{1,5,710}$ The C7 pedicle is often highly cortical and the dorsal landmarks for freehand placement can have significant variability., ${ }^{1,5,10,11,14}$ As compared to lateral mass and translaminar screws, studies have demonstrated the biomechanical superiority of pedicle screws, especially at the distal end of a construct. ${ }^{1,18,21,26}$ However, intraoperative evaluation of cervical pedicle screw placement can be difficult to assess using fluoroscopy alone..$^{2,5-8,13}$ There are often numerous technical challenges in obtaining a satisfactory view of the pedicles, including a patient's body habitus, shoulders, and positioning. ${ }^{5,711,14}$ As a result, surgeons have to rely on other techniques to allow for safe pedicle screw placement. ${ }^{14-17,20}$ Some surgeons avoid fixation at C7 and favor extending the instrumented construct to the upper thoracic spine. ${ }^{19,26,27,30}$

Intraoperative electromyographic (EMG) threshold testing is widely used to assist in determining the safety and accuracy of pedicle screws in the thoracolumbar spine. $3,4,9,15,22,24,25$ Although this modality has been shown to be safe and reliable in evaluating thoracolumbar pedicle screw placement, its generalizability to cervical pedicle screw placement is relatively unknown. ${ }^{15}$ Therefore the purpose of this study was 2-fold: first, to determine whether intraoperative neurophysiological monitoring may be useful for C7 pedicle screw fixation; and second, to establish the minimum EMG thresholds required to confirm adequate screw position.

\section{Methods}

After obtaining institutional review board approval, a retrospective review of prospectively collected data was undertaken. All adult patients who underwent posterior cervical decompression and fusion with placement of $\mathrm{C7}$ pedicle screws at our institution between January 2015 and March 2019 were identified. The intraoperative neurophysiological records of these patients were obtained. Demographic variables included age, sex, BMI, and preoperative diagnosis/indication for surgery. Preoperative MRI and/or CT scans were carefully reviewed for the presence of a vertebral artery (VA) within the foramen transversarium at $\mathrm{C}$. When this artery was present, $\mathrm{C} 7$ pedicle screws were not placed because of increased risk of vascular injury or stroke. Operative variables collected included levels decompressed, levels fused, and intraoperative EMG data from all C7 pedicle screw stimulations. Postoperative variables included all complications from surgery (i.e., acute or late postoperative infection, adjacent segment disease, and pseudarthrosis); need for revision (patients who have been offered additional surgery as well as those who have had additional surgery); and reason for revision.

Postoperatively, all patients underwent fine-cut (2-mm slice thickness) CT scanning with sagittal and coronal reconstructions from the occiput to T2. All CT scans were reviewed by a neuroradiologist who was unaware of intraoperative findings or EMG data, as well as by the operating surgeon. C7 pedicle screw position was analyzed and modeled according to the technique of Holdefer and colleagues..$^{15}$ Screws were assigned a grade depending on position: 1) ideal, 2) suboptimal but safe, or 3) potentially dangerous (Fig. 1).

Patients were seen postoperatively at 3 weeks, 3 months, 6 months, 1 year, and yearly thereafter. Standard cervical radiographs were obtained at those intervals. All clinical notes were reviewed and any need for revision or further surgery was recorded.

\section{Operative Procedure}

All patients underwent surgery in the prone position with the head maintained in $20-25$ pounds of traction by using Gardner-Wells tongs. Standard subperiosteal exposure was performed at the intended levels. Laminectomy was typically performed using the trough technique at the junction of the lamina and lateral mass. Subaxial lateral mass screws were placed using slightly modified An and Anderson techniques. When appropriate, thoracic pedicle screws were placed in a standard fashion. At T1, bicortical screws were placed intentionally; we put sufficiently long screws at $\mathrm{T} 1$ to attain purchase at the distal cortex. At C2, either pars or pedicle screws were placed.

Pedicle screws were placed at C7 by using one of several techniques. Typically, a high-speed burr was used to penetrate the outer cortex, often exposing a blush of pedicular bleeding at the intended starting point. The craniocaudal entry point is $2-3 \mathrm{~mm}$ below and at the mediolateral midline of the C6-7 joint. Once the outer cortex had been breached, the pedicle was cannulated by using either a 3.5-mm tap, or a power drill with guard set to $20 \mathrm{~mm}$. Our experience was that wider pedicles with cancellous bone were easily cannulated with a $3.5-\mathrm{mm}$ tap or power drill that would "suck" the bit down the pedicle. Thinner or more corticated pedicles required the use of a power drill.

C7 pedicle screws were directed in the sagittal plane perpendicular to the inclination of the $\mathrm{C} 7$ superior facet, and $20^{\circ}-30^{\circ}$ medially. If there was difficulty in placing the screw or anatomical landmarks were distorted, a partial laminotomy and foraminotomy was performed at the superior aspect of the $\mathrm{C} 7$ lamina, exposing the medial and superior edges of the pedicle. These trajectories were palpated with a ball-tipped probe, and if not done already, were tapped with a 3.5-mm tap. Placement of maximallength screws was always performed, with the intent of being completely embedded in bone. Careful preoperative imaging review is useful in approximating the length and width of planned C7 pedicle screws. Typically, $4.0-\mathrm{mm}$ screws of 24-30 mm length or 4.35-mm screws of 25- or 30-mm length were placed.

In cases in which the distal instrumented level was C7, such as in patients undergoing C3-7 decompression and 
instrumented fusion, great care was taken not to expose the C7-T1 joint and to preserve the C7-T1 interspinous ligaments. Laminectomy was performed at $\mathrm{C} 3-6$, and the cranial aspect of the $\mathrm{C} 7$ lamina was resected with a $3-\mathrm{mm}$ Kerrison rongeur, down to the $\mathrm{C} 7$ pedicle level, ensuring decompression past the C6-7 disc space (Fig. 2). In our experience, doing so may obviate the need to cross the cervicothoracic junction.

Intraoperative fluoroscopy was performed preoperatively to plan the incision and intraoperatively for level localization prior to laminectomy. Fluoroscopy was not typically used to place $\mathrm{C} 7$ or thoracic pedicle screws, or for any lateral mass screws. Intraoperative radiographs were taken once all screws were in place, in the lateral and true anteroposterior projections. The C7 level is often difficult to see on the lateral view, but appropriate true anteroposterior imaging is usually achievable.

\section{Neurophysiological Testing}

All posterior cervical surgeries were performed with neurophysiological monitoring. Somatosensory evoked potentials and EMG signals were monitored in all cases. If there was evidence of severe cord compression, especially with presence of $\mathrm{T} 2$ hyperintensity within the spinal cord consistent with contusion or myelomalacia, motor evoked potentials were monitored as well.

A Cadwell Cascade Pro was used to stimulate screws and record compound muscle action potentials (CMAPs) in the upper extremity. CMAPs were checked in the deltoid (C5); biceps (C5, C6); triceps (C6, C7); extensor digitorum $(\mathrm{C} 7, \mathrm{C} 8)$; and abductor pollicis brevis $(\mathrm{C} 8, \mathrm{~T} 1)$ with needle electrodes. The parameters used were as follows: pulse width $200 \mu \mathrm{sec}$, gain $200 \mu \mathrm{V} /$ division, HiCut filter of 3000, and LoCut filter of 10. The screws were electrically stimulated at $2-\mathrm{Hz}$ monophasic pulses by using a monopolar probe. Once C7 pedicle screws were placed, they were electrically stimulated using a Cadwell MultiStage Clip, and thresholds were determined by gradually increasing the stimulus from 0 to $20 \mathrm{~mA}$. Muscle relaxants were reversed or allowed to dissipate prior to stimulation and confirmed by a train-of-four response in the patient's hand.

\section{Anesthesia}

General endotracheal anesthesia is induced with propofol, lidocaine, fentanyl, midazolam, and succinylcholine. Baseline neurophysiological potentials data are then obtained, and confirmed once positioning is completed. At skin incision, we request supplementation of neuromuscular relaxation with rocuronium. Total intravenous anesthesia is typically maintained with remifentanyl and propofol infusion, as neuromuscular blockade is allowed to dissipate. If necessary, neuromuscular blockade may be pharmacologically reversed prior to screw stimulation. The mean arterial pressures are maintained above $65 \mathrm{~mm}$ $\mathrm{Hg}$, and within $20 \%$ of a patient's baseline.

\section{Results}

Twenty-five patients undergoing posterior cervical decompression and fusion with placement of $\mathrm{C} 7$ pedicle
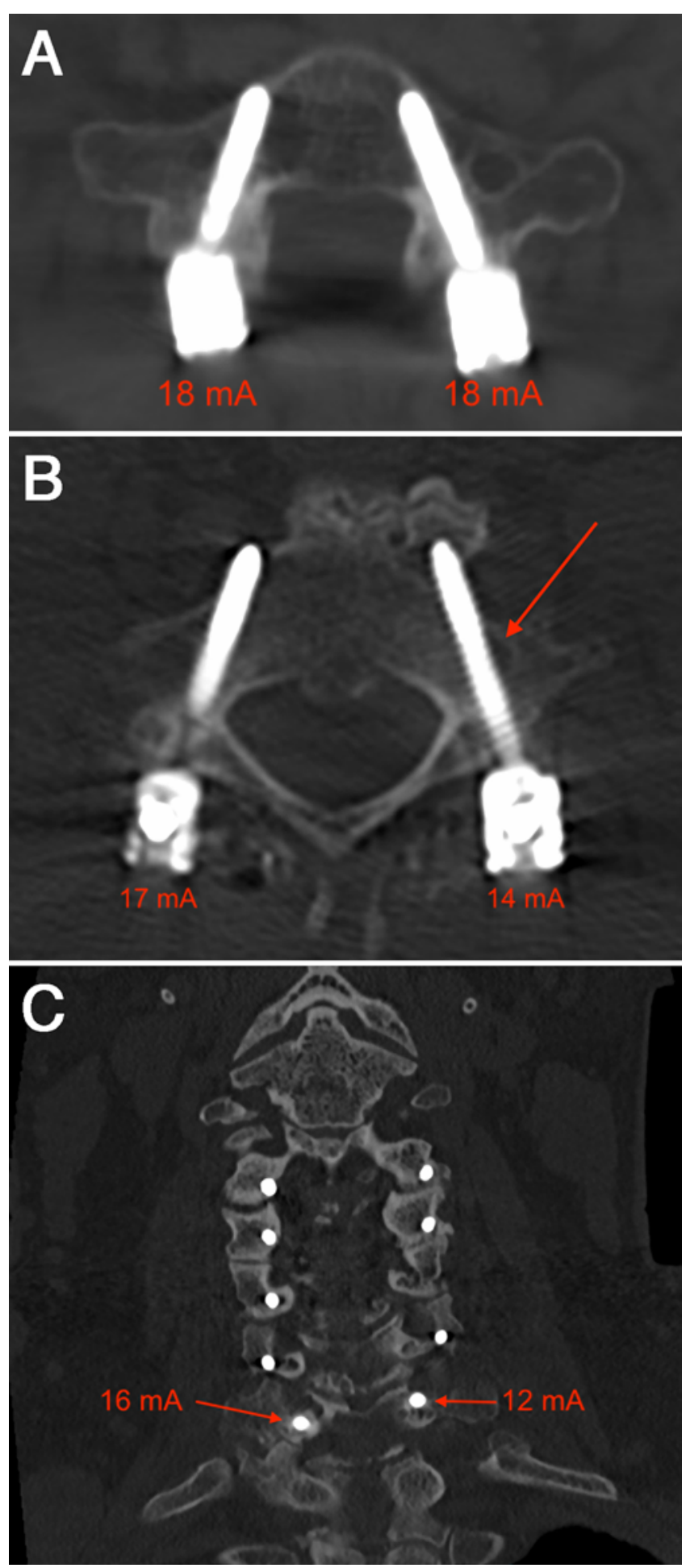

FIG. 1. A: Axial CT at the level of the C7 pedicle shows ideal placement of the pedicle screws; both screws stimulated at thresholds $>15 \mathrm{~mA}$. B: Axial CT at the level of the $\mathrm{C} 7$ pedicle shows suboptimal placement of the left pedicle screw, with infringement on the foramen transversarium (red arrow); this screw stimulated at $14 \mathrm{~mA}$. C: Coronal CT reconstruction shows cranial breach of the left $\mathrm{C} 7$ pedicle screw, which stimulated at $12 \mathrm{~mA}$. Screw stimulation parameters are listed below each screw in red lettering. Figure is available in color online only. 

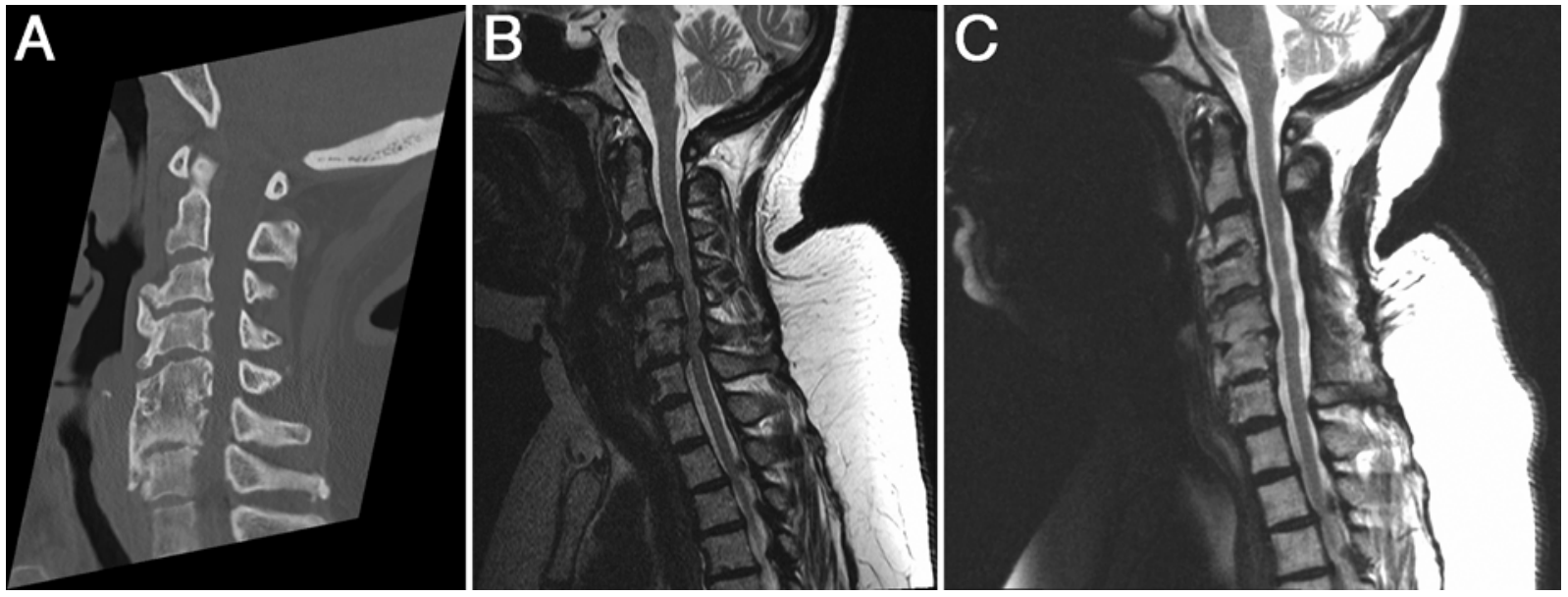

FIG. 2. A: Sagittal CT reconstruction showing extensive anterior osteophyte formation and OPLL precluding an anterior approach. B: Preoperative sagittal T2-weighted MRI shows cord compression and T2 hyperintensity, with stenosis extending to the C6-7 disc space. C: Two-year follow-up sagittal T2-weighted MRI shows cord decompression with preservation of the cervicothoracic junction.

screws during the stated time period were identified. Primary indications for surgery included multilevel stenosis with or without myelopathy, including OPLL ( $\mathrm{n}=$ 13), pseudarthrosis after prior anterior cervical discectomy and fusion with or without adjacent level stenosis $(\mathrm{n}=$ $5)$, central cord syndrome $(n=4)$, and deformity $(n=3)$. Multiple patients carried more than one diagnosis, such as OPLL, congenital stenosis, and central cord syndrome. The mean age was 61 years with a range from 45 to 79 years. Of these 25 patients, 19 had constructs terminating at C7 (Table 1).

Each patient had intraoperative recordings of CMAPs, and neurophysiological data are summarized in Table 2. Forty-three of $51(84.3 \%)$ C7 pedicle screws stimulated at thresholds $>15 \mathrm{~mA}$. Six of $51(11.8 \%) \mathrm{C} 7$ pedicle screws stimulated at thresholds between 11 and $15 \mathrm{~mA}$, and 2 of $51(3.9 \%)$ stimulated at thresholds $\leq 10 \mathrm{~mA}$.

In the patient in case 3 , the $\mathrm{C} 7$ pedicle screws stimulated at 11 and $14 \mathrm{~mA}$, respectively. Postoperative CT demonstrated lateral breach bilaterally, but there was no immediate clinical consequence (Fig. 3A). In the patient in case 16, the right $\mathrm{C} 7$ pedicle screw stimulated at $13 \mathrm{~mA}$, but the left stimulated at $>20 \mathrm{~mA}$ (Fig. 4A and B). The right screw was removed, the trajectory explored, and an early lateral breach was identified. A new more medial screw was placed that then stimulated at a threshold of $>20 \mathrm{~mA}$ (Fig. 4C and D). In the patient in case 19, the right $\mathrm{C} 7$ pedicle screw stimulated at $10 \mathrm{~mA}$, was removed, and the trajectory explored. An obvious breach was not identified, and the screw was replaced in the same trajectory. This patient awoke with a severe right $\mathrm{C} 7$ radiculopathy, and postoperative CT demonstrated a superior breach (Fig. 3B). He was returned to the operating room, and the C7 screw was stimulated, again at the $10-\mathrm{mA}$ threshold. A superior breach was confirmed after screw removal, and a generous C6-7 foraminotomy was performed to maximally decompress the $\mathrm{C} 7$ nerve root. A screw was not replaced, because there were pedicle screws placed at $\mathrm{T} 1$ and $\mathrm{T} 2$. Of note, the same patient's left $\mathrm{C} 7$ pedicle screw stimulated at $14 \mathrm{~mA}$, and was found to be laterally positioned on postoperative CT, but safe. Finally, in the patient in case 23 , the right $\mathrm{C} 7$ pedicle screw stimulated at $8 \mathrm{~mA}$. It was removed, and a medial breach was identified. Another pedicle screw could not be placed, and a lateral mass screw was placed instead. Other than the patient mentioned above who suffered a radiculopathy requiring revision, there were no neurological or in-hospital complications.

Postoperative CT was obtained in all patients, and all screw trajectories were scrutinized by the senior author and by a neuroradiologist who was unaware of intraoperative findings or EMG data. CT demonstrated ideal placement of the $\mathrm{C} 7$ pedicle screw in 40 of 43 instances in which EMG stimulation thresholds were $>15 \mathrm{~mA}$. In the remaining 3 cases, the trajectories were lateral (encroaching on the foramen transversarium) but safe because preoperative imaging confirmed absence of a VA. When the screw stimulation thresholds were between 11 and $15 \mathrm{~mA}, 5$ of 6 screws were lateral but safe, and in 1 instance showed a cranial breach, which was deemed potentially dangerous (Fig. 1C). In instances in which the screw stimulated at thresholds $\leq 10 \mathrm{~mA}$, all trajectories were potentially dangerous with neural compression.

The median clinical follow-up was 22.7 months (range 4-57 months). No patients were lost to follow-up. The patient in case 15 has suffered from pseudarthrosis at C6-7, with radiographic evidence of $\mathrm{C} 7$ screw loosening, and failure to form bridging bone at the C6-7 facet. Anterior cervical discectomy and fusion at C6-7 has been offered, but the patient has yet to undergo surgery. The patient in case 3, who had undergone C2-T1 decompression and fusion for central cord syndrome/OPLL, suffered from broken $\mathrm{T} 1$ pedicle screws bilaterally, but ultimately went on to fuse the C7-T1 facets successfully, and is clinically asymptomatic. Of the patients reaching 12-month followup, 22/23 have achieved solid fusion. No other patient has required or been offered revision surgery. There has not been any clinically apparent C7-T1 degeneration requir- 
TABLE 1. Patient demographics and results summary

\begin{tabular}{|c|c|c|c|c|c|c|c|c|}
\hline Case No. & Age (yrs) & Sex & Diagnosis & Levels & Rt C7 Threshold (mA) & Lt C7 Threshold (mA) & Rt C7 Position* & Lt C7 Position* \\
\hline 1 & 49 & M & CCS & C3-7 & 20 & 20 & 1 & 1 \\
\hline 2 & 58 & $\mathrm{~F}$ & Deformity & C2-7 & 20 & 18 & 1 & 1 \\
\hline 3 & 66 & $M$ & CCS, OPLL & $\mathrm{C} 2-\mathrm{T} 1$ & 14 & 11 & 2 & 2 \\
\hline 4 & 52 & $\mathrm{M}$ & CSM & C3-7 & 20 & 20 & 1 & 1 \\
\hline 5 & 79 & $\mathrm{M}$ & CSM, OPLL & C3-7 & 18 & 20 & 1 & 1 \\
\hline 6 & 64 & M & CSM & C3-7 & 20 & 20 & 1 & 1 \\
\hline 7 & 72 & $\mathrm{~F}$ & CSM & C3-7 & 18 & 18 & 1 & 1 \\
\hline 8 & 57 & $\mathrm{M}$ & CSM, CS & C3-7 & 20 & 20 & 1 & 1 \\
\hline 9 & 61 & $M$ & CSM, OPLL & C4-7 & 19 & 18 & 1 & 2 \\
\hline 10 & 60 & $\mathrm{M}$ & Deformity & $\mathrm{C} 2-\mathrm{T} 2$ & 18 & 16 & 1 & 1 \\
\hline 11 & 71 & $\mathrm{M}$ & PA, ASD & C4-7 & 18 & 17 & 1 & 2 \\
\hline 12 & 60 & M & CSM & C3-7 & 16 & 12 & 1 & 3 \\
\hline 13 & 50 & $\mathrm{~F}$ & CSM & C4-7 & 20 & 20 & 1 & 1 \\
\hline 14 & 74 & $M$ & CSM & $\mathrm{C} 5-\mathrm{T} 1$ & 16 & 20 & 2 & 1 \\
\hline 15 & 59 & $\mathrm{M}$ & CSM, OPLL & C3-7 & 20 & 18 & 1 & 1 \\
\hline 16 & 57 & $\mathrm{M}$ & PA, ASD & C4-7 & 13,20 & 20 & 2,1 & 1 \\
\hline 17 & 55 & $\mathrm{M}$ & Deformity & $\mathrm{C} 2-\mathrm{T} 4$ & 18 & 20 & 1 & 1 \\
\hline 18 & 72 & $\mathrm{M}$ & Synovial cyst & $\mathrm{C} 7-\mathrm{T} 1$ & 16 & 17 & 1 & 1 \\
\hline 19 & 59 & $\mathrm{M}$ & PA, ASD & $\mathrm{C} 5-\mathrm{T} 2$ & 10 & 14 & 3 & 2 \\
\hline 20 & 63 & $\mathrm{M}$ & CSM & C3-7 & 20 & 18 & 1 & 1 \\
\hline 21 & 66 & $\mathrm{~F}$ & CCS & C3-7 & 17 & 19 & 1 & 1 \\
\hline 22 & 52 & $\mathrm{M}$ & CSM & C3-7 & 20 & 20 & 1 & 1 \\
\hline 23 & 45 & M & PA, ASD & C5-7 & 8 & 20 & 3 & 1 \\
\hline 24 & 54 & $\mathrm{M}$ & CCS & C3-7 & 20 & 18 & 1 & 1 \\
\hline 25 & 59 & $\mathrm{~F}$ & PA, ASD & C4-7 & 17 & 14 & 1 & 2 \\
\hline
\end{tabular}

$\mathrm{ASD}=$ adult spinal deformity; $\mathrm{CCS}$ = central cord syndrome; $\mathrm{CS}=$ congenital stenosis; $\mathrm{CSM}=$ cervical spondylotic myelopathy; PA = pseudarthrosis.

* Screws were assigned a grade depending on position: 1, ideal; 2, suboptimal but safe; or 3, potentially dangerous (as described by Holdefer et al.).

ing extension of instrumentation to the thoracic spine in any patients whose construct terminated at C7 $(n=19)$, with follow-up extending nearly 60 months.

\section{Discussion}

The C7 vertebral body is morphometrically unique, because it represents the transition point from the subaxial cervical spine to the upper thoracic spine. ${ }^{1}$ It has the largest pedicles but relatively small lateral masses compared to other subaxial cervical levels. Studies have demonstrated biomechanical superiority of pedicle screws as compared to lateral mass or translaminar screws.,17,18,20,21,26 If C7 is the lowest instrumented vertebra, pedicle screw fixation is preferred-especially if the construct spans multiple levels, has no anterior fixation, or is in an osteoporotic individual-to avoid instrumentation failure..$^{17,18,21,26}$ However, placing C7 pedicle screws is technically demanding, and places multiple neural structures at risk..$^{14,17,21} \mathrm{C} 7$ pedicle screws are smaller and may be more cortical than proximal thoracic pedicle screws. ${ }^{17,21}$ Medial breach may lead to cord or C8 nerve root injury. Superior breach may result in C7 nerve root injury. Lateral breach may lead to VA injury or stroke in the $0.3 \%-18.4 \%$ of patients in whom the artery enters at $\mathrm{C} 7 .^{30}$
In light of this, all efforts must be given to maximize the safety of inserting C7 pedicle screws. First, careful preoperative review of imaging studies is crucial. Important considerations in preoperative planning include assessing the fundamental need to extend the construct to $\mathrm{C} 7$, estimating the length and diameter of $\mathrm{C} 7$ pedicle screws, and scrutinizing for the presence of a VA in the foramen transversarium (and in those instances possibly electing not to place a C7 pedicle screw).

Additionally, various intraoperative techniques have been described that potentially reduce the incidence of misplaced C7 pedicle screws, including intraoperative

TABLE 2. Intraoperative EMG threshold compared to postoperative $\mathrm{C} 7$ pedicle screw position

\begin{tabular}{cccc}
\hline \multirow{2}{*}{$\begin{array}{c}\text { EMG } \\
\text { Threshold }\end{array}$} & $\begin{array}{c}\text { Ideal } \\
\text { (grade 1) }\end{array}$ & $\begin{array}{c}\text { Suboptimal, } \\
\text { Safe (grade 2) }\end{array}$ & $\begin{array}{c}\text { Suboptimal, } \\
\text { Unacceptable (grade 3) }\end{array}$ \\
\hline $16-20 \mathrm{~mA}$ & 40 & 3 & 0 \\
\hline $11-15 \mathrm{~mA}$ & 0 & 5 & 1 \\
\hline $1-10 \mathrm{~mA}$ & 0 & 0 & 2 \\
\hline
\end{tabular}



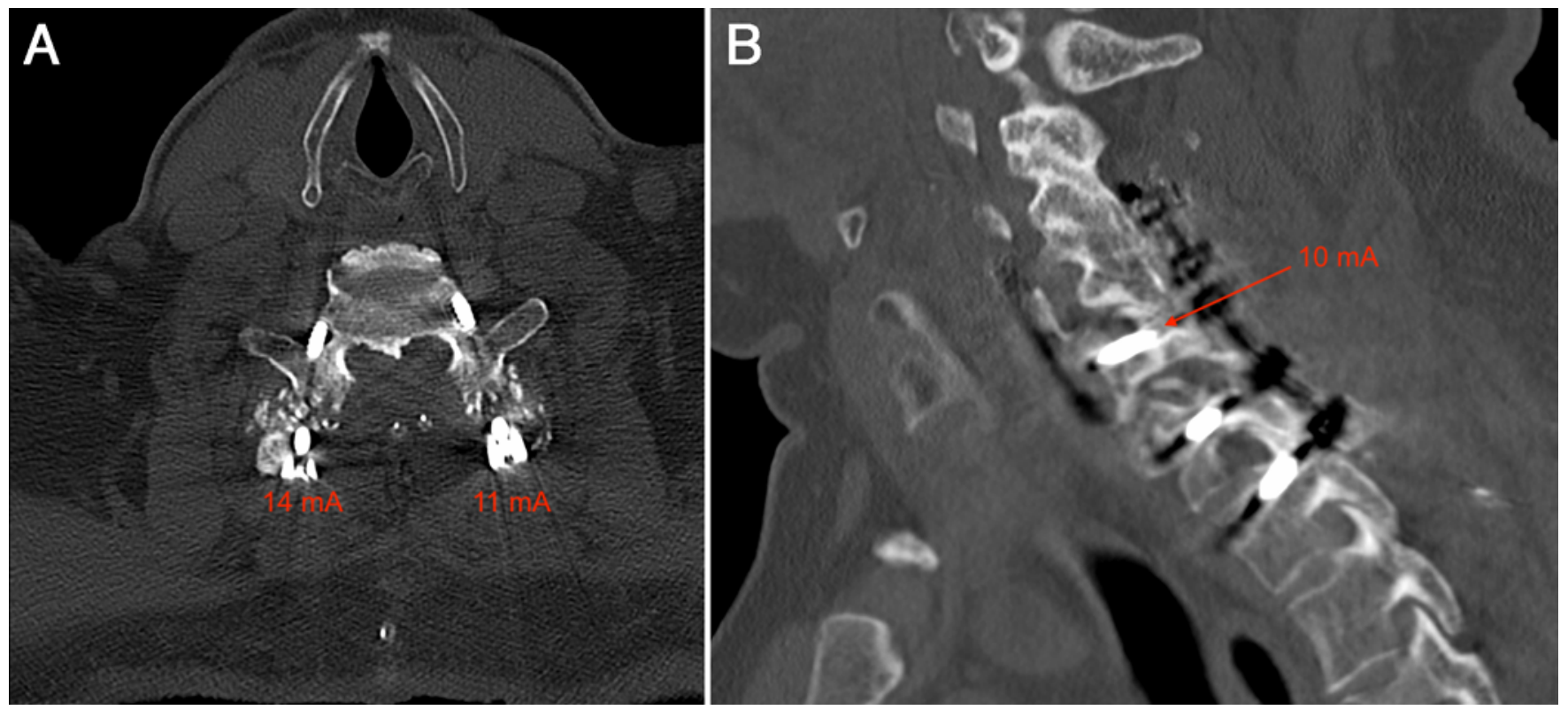

FIG. 3. A: Axial noncontrast CT in the patient in case 3 demonstrating bilateral $\mathrm{C} 7$ pedicle screws that stimulated at 11 and $14 \mathrm{~mA}$, respectively. Screw stimulation parameters are listed below each screw in red lettering. B: Sagittal noncontrast CT in the patient in case 19 demonstrating a superior pedicle breach with violation of the neuroforamen (red arrow). Figure is available in color online only.

fluoroscopy, 2D or 3D navigation, and screw stimulation. ${ }^{5-8,11,22}$ However, intraoperative fluoroscopy is challenging at the cervicothoracic junction, and stereotactic navigation, although accurate and helpful, can add to operating time and may not be readily available at some centers. ${ }^{5,14,16}$ Therefore, additional testing modalities such as C7 pedicle screw stimulation may be of benefit. ${ }^{8,11}$

Intraoperative pedicle screw stimulation has been shown to be a valuable tool in improving the safety of screw placement, especially in cases in which intraoperative fluoroscopy is difficult to interpret due to complex anatomy or body habitus.,2,18,21 The results of a recent meta-analysis determined that the most accurate threshold for safe pedicle screw placement in the lumbar spine was between 10 and $15 \mathrm{~mA}$, and in fact, many centers have adopted a standard threshold of $12 \mathrm{~mA} .^{3,4,6,9,22-25,29}$ Similarly, in the thoracic spine, EMG thresholds $<12 \mathrm{~mA}$ were found to correlate highly with pedicle screw malposition. ${ }^{25}$ Whereas EMG thresholds for thoracic and lumbar pedicle screws have been well defined, thresholds for the cervical spine have yet to be characterized.

To date, 2 studies have investigated the use of EMG stimulation thresholds in the cervical spine to evaluate pedicle screw placement, and these papers reached very different conclusions. ${ }^{8,15}$ Holdefer et al. performed triggered EMG thresholds at the deep edge of pilot holes drilled in 244 lateral masses and 113 pedicles (C7 and T1) in 32 patients. ${ }^{15}$ They determined that $5 \mathrm{~mA}$ was the critical threshold for potentially dangerous screw position. In contradistinction, in a study of 122 lateral mass screws and 25 C7 pedicle screws in 26 patients, Djurasovic and colleagues suggested that a screw stimulation threshold of $>$ $15 \mathrm{~mA}$ predicted acceptable screw position, with a positive predictive value of $>99 \%{ }^{8}$ They furthermore found that screw stimulation thresholds of $<10 \mathrm{~mA}$ were associated with screw malposition in the majority of cases, and recommended prompt exploration, repositioning, or removal. If the stimulation threshold was between 10 and $15 \mathrm{~mA}$, they recommended exploration, although this threshold was usually associated with adequate screw placement.

Overall, our study confirms the findings of Djurasovic, in that stimulation thresholds of $>15 \mathrm{~mA}$ were predictive of satisfactory screw placement. ${ }^{8}$ Forty of 43 screws whose trajectories stimulated at the threshold of $>15 \mathrm{~mA}$ were found to be ideal on postoperative CT, whereas the remaining 3 were suboptimal but safe. Stimulation thresholds between 11 and $15 \mathrm{~mA}$ were associated with lateral trajectories that occasionally required revision. All screws with stimulation thresholds $\leq 10 \mathrm{~mA}$ were found to be potentially dangerous and/or required revision.

There are significant methodological differences between our study and those of Holdefer et al. and Djurasovic et al. that may explain the disparate threshold values reached by the authors. First, Holdefer and colleagues stimulated pilot holes rather than the actual screw. Pilot hole testing may detect an unsafe trajectory before inserting the pedicle screw and potentially harming the nerve roots. However, this method cannot detect pedicle screw breach. In addition, Holdefer et al. used longer pulse duration widths in their study than Djurasovic et al. (200 usec vs $50 \mu \mathrm{sec})$. Prior literature has suggested that longer pulse widths (300 $\mu \mathrm{sec})$ provide more accurate detection, but $200 \mu \mathrm{sec}$ has a higher sensitivity. ${ }^{24,28,29}$

Regardless of the actual threshold, the results of this study complement those of Holdefer et al. and Djurasovic and colleagues, in that the addition of EMG threshold testing improved the safety and accuracy of cervical pedicle screw placement. Holdefer et al. concluded that, 


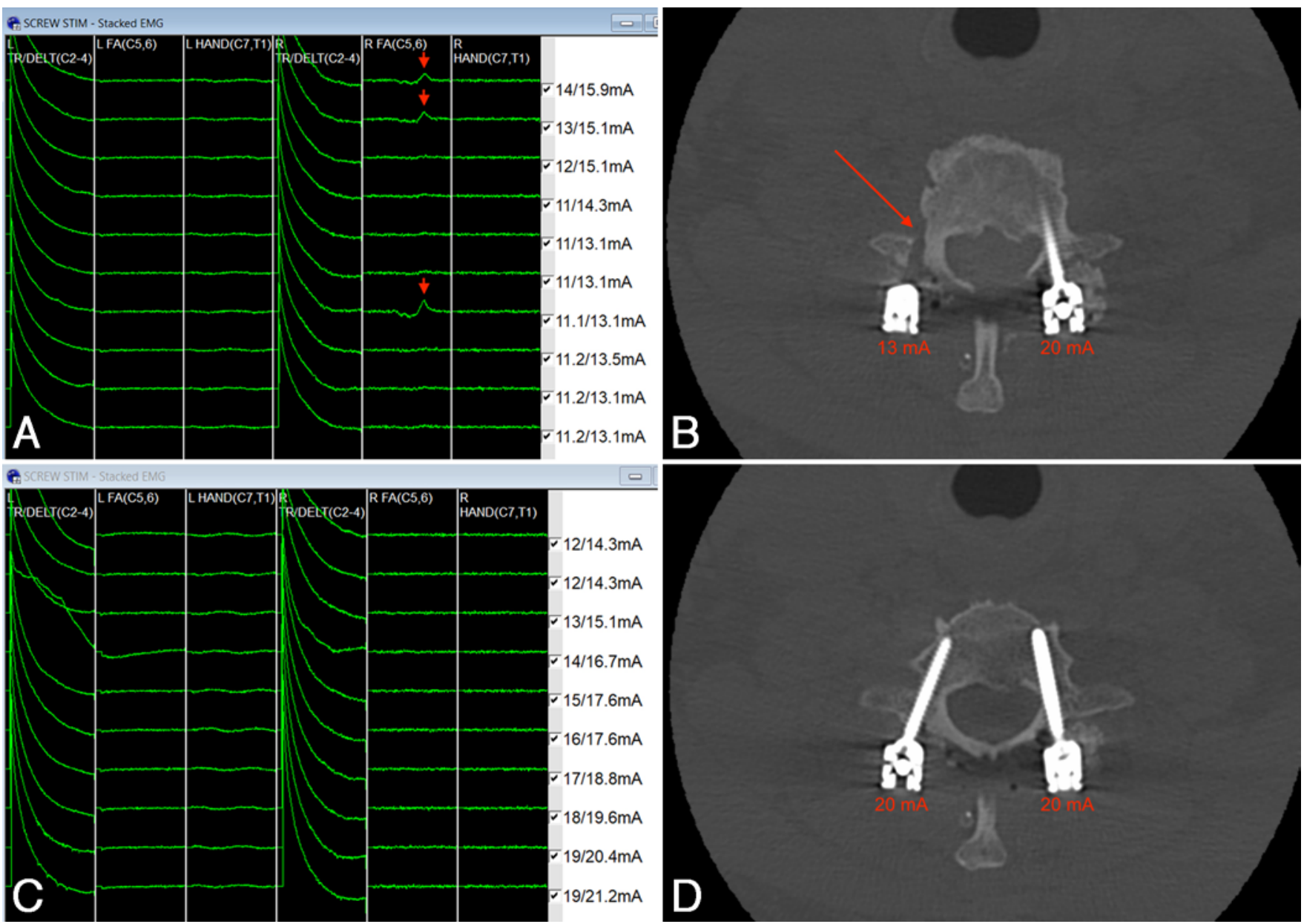

FIG. 4. A: Screenshots taken from intraoperative right $C 7$ pedicle screw stimulation. The right $C 7$ pedicle screw initially stimulated at $13 \mathrm{~mA}$, which replicated at 15 and $16 \mathrm{~mA}$ (red arrows), prompting exploration. B: Axial noncontrast CT demonstrating the initial trajectory of the right $\mathrm{C} 7$ pedicle screw, which was found to be lateral and subsequently revised (red arrow). C: An early lateral breach was identified and a new more medial screw was placed, which then stimulated at a threshold of $>20 \mathrm{~mA}$. D: Axial noncontrast CT demonstrating final position of the right C7 pedicle screw. Screw stimulation parameters are listed below each screw in red lettering. Figure is available in color online only.

when comparing the control group where the surgeon was blinded to the EMG testing results to the test group where the surgeon was notified of the EMG results, $4.5 \%$ of the control group had misplaced screws whereas $0 \%$ had misplaced screws in the experimental group. ${ }^{15}$ In all 4 cases in the experimental group, the screws were removed and either left out or replaced in new trajectories. This reduction results in a number needed to treat of 22 to prevent a dangerous pedicle screw. Similarly, Djurasovic et al. concluded that that the addition of screw stimulation provided a "valuable aid to surgeons in the accurate placement of posterior cervical instrumentation."

Limitations of this study include a relatively small sample size, low incidence of misplaced screws, and overall limitations of EMG testing. The small sample size decreases the power of the study. False-negative EMG thresholds may occur from the stimulation of the screw or pilot hole and the nerve root in chronic compression or neuropathy or in a "wet" environment. ${ }^{16}$ A false-positive EMG threshold may occur in the setting of a pedicle screw repositioned due to a prior medial breach, owing to the existing violation of the medial cortex. In these situations, we have placed a small Gelfoam sponge in the more medial trajectory to mitigate current spread and replaced the screw to a more lateral trajectory. In cases in which the patient's anatomy prevented the replacement of a pedicle screw, we converted to a lateral mass screw. Last, based on a meta-analysis of numerous studies, EMG testing is associated with low overall sensitivity, with up to $22 \%$ of misplaced screws not detectable by EMG methods. ${ }^{28}$ These limitations notwithstanding, the major strength of this study is the homogeneity of the test subject: only C7 pedicle screws were stimulated. Previous studies had grouped lateral mass and pedicle screws, as well as C7 with $\mathrm{T} 1$ pedicle screws, and it was our intention to define the crucial threshold solely for the C7 pedicle. ${ }^{8,15}$

\section{Conclusions}

EMG threshold testing is a useful addition to the surgeon's armamentarium in placing safe $\mathrm{C} 7$ pedicle screws. It can alert the surgeon intraoperatively to the possibility of 
a misplaced $\mathrm{C} 7$ pedicle screw, and potentially avoid neural injury or reduce the need for revision surgery. In our experience, EMG thresholds correlated well with postoperative CT findings. Stimulation thresholds $>15 \mathrm{~mA}$ were always associated with satisfactory pedicle screw placement. Stimulation thresholds between 11 and $15 \mathrm{~mA}$ mostly indicated suboptimal, but clinically acceptable, screw positions. For these values we recommend exploration of the trajectory. In our experience stimulation thresholds $\leq$ $10 \mathrm{~mA}$ were always associated with potentially dangerous screws, and in these situations we recommend prompt exploration, repositioning, or removal. We encourage future studies with larger sample sizes to confirm the results of this study.

\section{References}

1. Abdullah KG, Nowacki AS, Steinmetz MP, Wang JC, Mroz TE: Factors affecting lateral mass screw placement at C-7. J Neurosurg Spine 14:405-411, 2011

2. An HS, Gordin R, Renner K: Anatomic considerations for plate-screw fixation of the cervical spine. Spine (Phila Pa 1976) 16 (10 Suppl):S548-S551, 1991

3. Bose B, Wierzbowski LR, Sestokas AK: Neurophysiologic monitoring of spinal nerve root function during instrumented posterior lumbar spine surgery. Spine (Phila Pa 1976) 27:1444-1450, 2002

4. Calancie B, Madsen P, Lebwohl N: Stimulus-evoked EMG monitoring during transpedicular lumbosacral spine instrumentation. Initial clinical results. Spine (Phila Pa 1976) 19:2780-2786, 1994

5. Clifton W, Edwards S, Louie C, Dove C, Damon A, Nottmeier E, et al: Techniques and tips for freehand placement of C7 pedicle screws with respect to cervicothoracic constructs: 2-dimensional operative video. Oper Neurosurg (Hagerstown) [epub ahead of print], 2019

6. de Blas G, Barrios C, Regidor I, Montes E, Burgos J, PizáVallespir G, et al: Safe pedicle screw placement in thoracic scoliotic curves using t-EMG: stimulation threshold variability at concavity and convexity in apex segments. Spine (Phila Pa 1976) 37:E387-E395, 2012

7. Desai S, Sethi A, Ninh CC, Bartol S, Vaidya R: Pedicle screw fixation of the $\mathrm{C} 7$ vertebra using an anteroposterior fluoroscopic imaging technique. Eur Spine J 19:1953-1959, 2010

8. Djurasovic M, Dimar JR II, Glassman SD, Edmonds HL, Carreon LY: A prospective analysis of intraoperative electromyographic monitoring of posterior cervical screw fixation. J Spinal Disord Tech 18:515-518, 2005

9. Duffy MF, Phillips JH, Knapp DR, Herrera-Soto JA: Usefulness of electromyography compared to computed tomography scans in pedicle screw placement. Spine (Phila Pa 1976) 35:E43-E48, 2010

10. Ebraheim NA, Xu R, Stanescu S, Yeasting RA: Anatomic relationship of the cervical nerves to the lateral masses. Am J Orthop 28:39-42, 1999

11. Esses SI, Sachs BL, Dreyzin V: Complications associated with the technique of pedicle screw fixation. A selected survey of ABS members. Spine (Phila Pa 1976) 18:2231-2239, 1993

12. Fehlings MG, Tetreault LA, Riew KD, Middleton JW, Aarabi B, Arnold PM, et al: a clinical practice guideline for the management of patients with degenerative cervical myelopathy: recommendations for patients with mild, moderate, and severe disease and nonmyelopathic patients with evidence of cord compression. Global Spine J 7 (3 Suppl):70S-83S, 2017

13. Glassman SD, Dimar JR, Puno RM, Johnson JR, Shields CB,
Linden RD: A prospective analysis of intraoperative electromyographic monitoring of pedicle screw placement with computed tomographic scan confirmation. Spine (Phila Pa 1976) 20:1375-1379, 1995

14. Heller JG, Silcox DH III, Sutterlin CE III: Complications of posterior cervical plating. Spine (Phila Pa 1976) 20:24422448, 1995

15. Holdefer RN, Heffez DS, Cohen BA: Utility of evoked EMG monitoring to improve bone screw placements in the cervical spine. J Spinal Disord Tech 26:E163-E169, 2013

16. Holland NR, Lukaczyk TA, Riley LH III, Kostuik JP: Higher electrical stimulus intensities are required to activate chronically compressed nerve roots. Implications for intraoperative electromyographic pedicle screw testing. Spine (Phila Pa 1976) 23:224-227, 1998

17. Joaquim AF, Mudo ML, Tan LA, Riew KD: Posterior subaxial cervical spine screw fixation: a review of techniques. Global Spine J 8:751-760, 2018

18. Jones EL, Heller JG, Silcox DH, Hutton WC: Cervical pedicle screws versus lateral mass screws. Anatomic feasibility and biomechanical comparison. Spine (Phila Pa 1976) 22:977-982, 1997

19. Kennamer BT, Arginteanu MS, Moore FM, Steinberger AA, Yao KC, Gologorsky Y: Complications of poor cervical alignment in patients undergoing posterior cervicothoracic laminectomy and fusion. World Neurosurg 122:e408-e414, 2019

20. Lee GW, Kim HJ, Yeom JS, Uh JH, Park JH, Lee JH, et al: Feasibility study of free-hand technique for pedicle screw insertion at C7 without fluoroscopy-guidance. Asian Spine J 10:38-45, 2016

21. Liu Y, Hu JH, Yu KY: Pedicle screw fixation for cervical spine instability: clinical efficacy and safety analysis. Chin Med J (Engl) 122:1985-1989, 2009

22. Mikula AL, Williams SK, Anderson PA: The use of intraoperative triggered electromyography to detect misplaced pedicle screws: a systematic review and meta-analysis. J Neurosurg Spine 24:624-638, 2016

23. Parker SL, Amin AG, Farber SH, McGirt MJ, Sciubba DM, Wolinsky JP, et al: Ability of electromyographic monitoring to determine the presence of malpositioned pedicle screws in the lumbosacral spine: analysis of 2450 consecutively placed screws. J Neurosurg Spine 15:130-135, 2011

24. Raynor BL, Lenke LG, Bridwell KH, Taylor BA, Padberg AM: Correlation between low triggered electromyographic thresholds and lumbar pedicle screw malposition: analysis of 4857 screws. Spine (Phila Pa 1976) 32:2673-2678, 2007

25. Regidor I, de Blas G, Barrios C, Burgos J, Montes E, GarcíaUrquiza S, et al: Recording triggered EMG thresholds from axillary chest wall electrodes: a new refined technique for accurate upper thoracic (T2-T6) pedicle screw placement. Eur Spine J 20:1620-1625, 2011

26. Rhee JM, Kraiwattanapong C, Hutton WC: A comparison of pedicle and lateral mass screw construct stiffnesses at the cervicothoracic junction: a biomechanical study. Spine (Phila Pa 1976) 30:E636-E640, 2005

27. Schroeder GD, Kepler CK, Kurd MF, Mead L, Millhouse PW, Kumar P, et al: Is it necessary to extend a multilevel posterior cervical decompression and fusion to the upper thoracic spine? Spine (Phila Pa 1976) 41:1845-1849, 2016

28. Toleikis JR, Skelly JP, Carlvin AO, Toleikis SC, Bernard TN, Burkus JK, et al: The usefulness of electrical stimulation for assessing pedicle screw placements. J Spinal Disord 13:283-289, 2000

29. Welch WC, Rose RD, Balzer JR, Jacobs GB: Evaluation with evoked and spontaneous electromyography during lumbar instrumentation: a prospective study. J Neurosurg 87:397402, 1997

30. Yuk FJ, Rasouli JJ, Arginteanu MS, Steinberger AA, Moore 
FM, Yao KC, et al: The case for T2 pedicle subtraction osteotomy in the surgical treatment of rigid cervicothoracic deformity. J Neurosurg Spine [epub ahead of print October 25, 2019. DOI: 10.3171/2019.7.SPINE19350]

\section{Disclosures}

The authors report no conflict of interest concerning the materials or methods used in this study or the findings specified in this paper.

\section{Author Contributions}

Conception and design: all authors. Acquisition of data: Gologorsky, Kennamer, Moore, Steinberger, Yao, Syed, Arginteanu. Analysis and interpretation of data: Gologorsky, Rasouli. Drafting the article: Gologorsky, Rasouli, Kennamer. Critically revising the article: Gologorsky, Rasouli, Kennamer. Reviewed submitted version of manuscript: Gologorsky, Rasouli, Kennamer.
Approved the final version of the manuscript on behalf of all authors: Gologorsky. Statistical analysis: Kennamer. Administrative/technical/material support: Gologorsky, Rasouli, Yao. Study supervision: Gologorsky, Rasouli, Moore, Steinberger, Yao, Syed, Arginteanu.

\section{Correspondence}

Yakov Gologorsky: Mount Sinai Health System, New York, NY. yakov.gologorsky@mountsinai.org. 